\title{
Oral hygiene practices and their socio-demographic correlates among Nepalese adult: evidence from non communicable diseases risk factors STEPS survey Nepal 2013
}

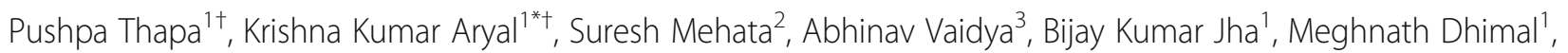
Shaili Pradhann ${ }^{4}$, Purushottam Dhakal ${ }^{1}$, Arpana Pandit ${ }^{1}$, Achyut Raj Pandey ${ }^{1}$, Bihungum Bista ${ }^{1}$, Ava Upadhyay Pokhrel ${ }^{5}$ and Khem Bahadur Karki ${ }^{1}$

\begin{abstract}
Background: Oral diseases remain a significant public health problem in Nepal, as do oral health behaviours. Sociodemographic factors play a crucial role in driving oral hygiene practices. This study aims to identify oral hygiene practices and associated socio-demographic factors in Nepalese population.

Methods: This descriptive, cross-sectional study recruited 4200 adults (15-69 years) through multistage cluster sampling. Data obtained from the WHO NCD STEPS instrument version 2.2 were analysed in STATA 13.0 using complex sample weighted analysis.

Results: Prevalence of cleaning teeth at least once a day was $94.9 \%$ (95 \% Cl: 93.7-95.9), while that of cleaning teeth at least twice a day was $9.9 \%$ (95 \% Cl: 8.2-11.9). Use of fluoridated toothpaste was seen among $71.4 \%$ (95\% Cl: 67.9-74.7) respondents. A $3.9 \%$ (95 \% Cl: 3.1-5.0) made a dental visit in the last 6 months.

The 45-69 years age group had lesser odds of cleaning teeth at least once a day (AOR: $0.4 ; 95 \%$ Cl: 0.2-0.8), in comparison to 15-29 years age group. Women had greater odds of cleaning teeth at least twice a day (AOR: 1.7; $95 \% \mathrm{Cl}: 1.1-2.4)$ and having visited a dentist in the last 6 months (AOR: 2.2; $95 \%$ Cl: 1.2-3.8) compared to men. With reference to rural residents, urban population had higher odds of using fluoridated toothpaste (AOR: $2.3 ; 95 \%$ Cl: 1.4-3.4) and making a dental visit within the last 6 months (AOR: 1.9; $95 \%$ Cl:1.1-3.6). Inhabitants of the Terai had five-fold (AOR: 4.9; $95 \% \mathrm{Cl}$ : 3.1-7.8) greater odds of cleaning teeth once per day than did hill residents. Those with higher education had greater odds than non-formal education holders of cleaning teeth at least once a day (AOR: 9.0; $95 \% \mathrm{Cl}: 2.9-27.7$ ), cleaning teeth at least twice a day (AOR: 5.6; 95 \% Cl: 2.9-10.6), using fluoridated toothpaste (AOR: 13.9; 95 \% Cl: 8.4-23.1), and having visited a dentist in the last 6 months (AOR: $2.8 ; 95 \%$ Cl: 1.4-5.4).
\end{abstract}

Conclusions: Cleaning teeth at least once a day is widely prevalent in Nepal and a substantial number of population use fluoridated toothpaste. However, cleaning teeth twice a day and visiting a dentist is less common. Being women, Terai residents, urban residents, and educated were significantly associated with oral hygiene practices assessed in this study.

Keywords: Non-communicable diseases risk factors, Nepal, Oral health, Oral hygiene practices, Socio-demographic factors, STEPS survey

\footnotetext{
* Correspondence: krish.aryal@gmail.com

${ }^{\dagger}$ Equal contributors

${ }^{1}$ Nepal Health Research Council, Ramshahpath, Kathmandu 44600, Nepal

Full list of author information is available at the end of the article
} 


\section{Background}

Oral diseases are a major public health concern globally [1], and profoundly impact the well being and daily social lives of people [2]. Worldwide, 3.9 billion people are affected by oral diseases [3]. Disadvantaged and poor populations are the most vulnerable worldwide [1].

Poor oral hygiene is recognised as one of the greatest risk factors for oral diseases [1]. Evidence shows that brushing teeth at least twice a day and making dental visits help to counter oral health problems [4]. Oral hygiene practices are in turn influenced by sociodemographic environment $[1,5]$. Higher education $[6,7]$, socioeconomic status [8] have been found to contribute to oral hygiene habits and utilisation of oral health services.

Despite being highly preventable, a substantial proportion of the Nepalese population experiences oral health problems [9], especially poor and marginalized individuals [10]. One-third of Nepalese adults have been found to have self-reported dental caries [11]. Modernisation and changes in dietary patterns have all contributed to the poor oral health status in Nepal [10].

There have been very few studies documenting oral hygiene practices and related socio-demographic factors in the context of Nepal. Being one of the poorest countries [12], the cost of dental services is prohibitive for the majority of the Nepalese populace [10]. Against this background, the identification of oral health practices and related socio-demographic factors in Nepal is crucial to the design and implementation of appropriate oral health promotion interventions. The present study thus assessed oral hygiene practices and its socio-demographic correlates among the adult Nepalese population.

\section{Methods}

This study is a part of a national STEPS survey on noncommunicable diseases (NCD) risk factors which had World Health Organization (WHO) recommended oral health module to identify risk factors on oral health.

\section{Study design and population}

This was a nationally representative descriptive, crosssectional study conducted from January to June 2013, assigning adult men and women aged 15-69 years as the study population. Only those who had been living at their current place of residence for at least 6 months were included in the study. The study excluded too frail and mentally ill who were unable to provide responses. We also excluded people with physical disability as anthropometric measurements were also one of the major variables to be measured for the main study even though this paper does not make use of that particular variable. Further, we excluded those with primary places of residence in military bases or group dwellings; and those residing in hospitals, prisons, nursing homes or other institutions.

\section{Sampling method}

Multistage cluster sampling was employed and carried out at three stages as explained elsewhere [13]. Sample size of 4,200 was calculated using the prevalence of low fruit and vegetables consumption (61.9\%) from the NCD Risk Factors Survey 2008 [14] as baseline level of indicator, with $95 \%$ confidence level, $5 \%$ of absolute error, 1.5 design effect and $80 \%$ expected response.

Ilakas (sub district units comprising of village development committees (VDCs) and/or whole or part of municipalities) made the primary sampling units (PSUs). Individual wards (lowest administrative division under the VDCs and municipalities) were the secondary sampling units (SSUs) and individual households made the tertiary sampling units (TSUs). PSUs and SSUs were selected using probability proportionate to size (PPS) sampling technique and TSUs were selected using systematic random sampling. One eligible respondent (15-69 years) from each selected household was selected using the Kish method and approached for inclusion in the study [15]. The response rate was $98.6 \%$ (4,143 adults participated in STEP I of the survey which included measurement of behavioural risk factors including that of oral health).

\section{Data collection tools and technique}

The survey was conducted using the WHO NCD STEPS instrument version 2.2 [16], which prescribes three steps for measuring NCD risk factors. STEP I measures behavioural risk factors, STEP II covers physical measurements, and STEP III measures biological risk factors. Oral hygiene-related behavior is covered in STEP I as one of the optional modules, of which we used all the questions prescribed in the stepwise approach to surveillance [16]. We report four individual oral health behaviors as assessed in the NCD Risk Factors STEPS Survey Nepal 2013, which are: cleaning teeth at least once a day, cleaning teeth at least twice a day, using fluoridated tooth paste, and having visited a dentist in the last 6 months.

A week-long training was conducted for enumerators and field supervisors. All the enumerators came from a health background, and supervisors held a bachelor degree in public health with substantial experience in research work. Focused training agendas were: interview techniques, sampling process, household and individual selection, use of different kinds of templates and forms in the survey, use and care of personal digital assistants (PDAs), and detailed explanations of the questionnaire and physical measurement techniques. Supervisors were also trained on downloading data from PDAs and handling issues with PDAs. The STEPS instrument was 
translated into Nepali and validated through a pilot study carried out in Kirtipur Municipality, Kathmandu, among 20 households. Necessary changes were made to the questionnaire; the revised version was then endorsed by a Steering Committee prior to field use. Enumerators carried out data collection using PDAs. Frequent monitoring and supervision was carried out from the central level during data collection.

\section{Major variables in the study \\ Education level}

Education level was defined based on the literacy status of the respondents. Respondents with non-formal education were those who did not attend any formal education. Other levels were categorized as per the number of school years: primary education (5 years of schooling completed), secondary education (10 years of schooling completed), and higher secondary or above (more than or equal to 12 years of schooling completed).

\section{Place of residence}

Based on the central bureau of statistics, we categorized village development committees (VDCs) as rural and municipalities as urban in this study.

\section{Ecological belt}

Nepal is geographically divided into three belts north to south based on altitude. Mountains, hills and the Terai are three ecological belts where mountains refers to the high mountain region, hills refers to adjacent region in a lower altitudinal belt while the Terai refers to the lowest terrain in the country ranging from 70 to $700 \mathrm{~m}$ above the sea level.

\section{Data analysis}

Data collected in PDAs were exported to Microsoft Excel 2007, cleaned with SPSS 16.0, and analysed with STATA 13.0 to carry out complex sample weighted analysis. To measure the association between oral hygiene practices and socio-demographic factors, adjusted odds ratios (AOR) were estimated through logistic regression models. We adjusted age, gender, ecological belt, place of residence, education level and marital status in the logistic regression models. Weighting was done so as to be able to generalise the findings to adults aged 15-69 years across the country. As the study used multistage sampling, weight was calculated by using the probability of selections of PSUs, SSUs, TSUs and individual respondents. Firstly, the probabilities of selections at the individual level were calculated and multiplied to get a final probability. The inverse of the selection probability was then used as a sample weight.

\section{Results}

A total of 4,143 adults participated in STEP I, which contained the module on oral health. We report the results for 4143 observations for all the variables except marital status where we had two missing responses.

\section{Oral hygiene practices}

Of the total, almost $95 \%$ reported cleaning teeth at least once a day, while around $10 \%$ reported cleaning teeth twice a day. Among the total population, $71 \%$ used fluoridated toothpaste and only $4 \%$ visited dentist in the last 6 months (Table 1).

\section{Distribution of oral hygiene practices across various socio-demographic strata}

Around $98 \%$ of the people aged $15-29$ years cleaned teeth at least once a day, while prevalence of cleaning teeth at least twice a day was also the highest among the same age group. A similar proportion of men and women cleaned teeth at least once a day and at least twice a day. Nearly, all people from the Terai, from urban areas, with secondary education or above and never married cleaned teeth at least once a day. Prevalence of cleaning teeth at least twice a day was found $16 \%$ among urban inhabitants, $19 \%$ among higher secondary or above education holders and $16 \%$ among never married individuals. Use of fluoridated toothpaste was most common among the youngest age group - 15-29 year olds (79\%), urban dwellers (85\%), higher secondary or above education holders (93\%), and never married individuals (85\%) (Table 1 ).

\section{Socio-demographic correlates of oral hygiene practices Cleaning teeth at least once a day}

The odds of cleaning teeth at least once a day was five times higher among people from the Terai compared to the hill residents. The odds of cleaning teeth at least once a day increased with increased level of education (Table 2).

\section{Cleaning teeth at least twice a day}

Women had 1.7 times higher odds of cleaning teeth at least twice a day than men. The odds of cleaning teeth at least twice a day rose with educational level similar to cleaning teeth at least once a day. Compared to those with non-formal education, odds of cleaning teeth at least twice a day was 2 times higher among primary education holders, four times higher among secondary education holders, and 5.6 times higher among higher secondary and above education holders (Table 2).

\section{Use of fluoridated toothpaste}

Residents of the Terai had lesser odds of using fluoridated toothpaste than hill-dwelling residents (AOR: 0.7; 95 \% CI: 0.4-0.9). Urban inhabitants had higher odds of using fluoridated toothpaste use (AOR: 2.3; 95 \% CI: 
Table 1 Distribution of oral hygiene practices by socio-demographic characteristics

\begin{tabular}{|c|c|c|c|c|c|}
\hline \multirow[t]{2}{*}{ Characteristics } & \multirow[t]{2}{*}{ N (un-weighted \%) } & $\begin{array}{l}\text { Cleaning teeth at } \\
\text { least once a day }\end{array}$ & \multirow{2}{*}{$\begin{array}{l}\text { Cleaning teeth at } \\
\text { least twice a day } \\
\%(95 \% \mathrm{Cl})\end{array}$} & \multirow{2}{*}{$\begin{array}{l}\text { Use of fluoridated } \\
\text { toothpaste } \\
\%(95 \% \mathrm{Cl})\end{array}$} & \multirow{2}{*}{$\begin{array}{l}\text { Visited a dentist withir } \\
\text { the last } 6 \text { months } \\
\%(95 \% \mathrm{Cl})\end{array}$} \\
\hline & & $\%(95 \%$ Cl) & & & \\
\hline \multicolumn{6}{|l|}{ Age Group (Years) } \\
\hline $15-29$ & $972(23.5)$ & 97.9(96.8-98.7) & 13.1(10.4-16.3) & 79.3(75.1-82.9) & $2.8(1.8-4.4)$ \\
\hline $30-44$ & 1558 (37.6) & 94.8(92.9-96.2) & $8.2(6.3-10.5)$ & $69.1(64.6-73.2)$ & $4.0(2.8-5.6)$ \\
\hline $45-69$ & 1613 (38.9) & 89.6(87.1-91.6) & $6.2(4.6-8.2)$ & $57.6(52.6-62.4)$ & $6.1(4.5-7.6)$ \\
\hline \multicolumn{6}{|l|}{ Gender } \\
\hline Men & $1336(32.2)$ & 95.7(94.3-96.8) & $9.6(7.3-12.4)$ & 75.7(71.6-79.9) & $3.1(1.8-4.8)$ \\
\hline Women & $2807(67.8)$ & $94.1(92.4-95.4)$ & 10.3(8.2-12.3) & $66.1(62.3-69.7)$ & $4.8(3.8-6.2)$ \\
\hline \multicolumn{6}{|l|}{ Ecological Belt } \\
\hline Mountain & $300(7.1)$ & $84.3(72.6-91.5)$ & $4.2(0.6-2.3)$ & $70.7(59.1-80.2)$ & $4.6(1.5-12.6)$ \\
\hline Hill & $1800(42.9)$ & $92.60(90.3-94.3)$ & 10.2(7.8-13.1) & 75.2(70.4-79.6) & $3.9(2.5-6.0)$ \\
\hline Terai & $2100(50.0)$ & 98.2(97.4-98.7) & 11.0(7.9-13.7) & $67.0(61.3-72.3)$ & $3.9(2.9-5.3)$ \\
\hline \multicolumn{6}{|l|}{ Place of Residence } \\
\hline Rural & $3422(18.5)$ & 94.3(92.9-95.4) & $8.5(6.8-10.6)$ & $67.3(63.3-71.1)$ & $3.3(2.4-4.5)$ \\
\hline Urban & $778(81.5)$ & $97.2(94.6-98.6)$ & $16.0(11.2-22.1)$ & 85.4(79.9-89.8) & $6.7(4.4-10.0)$ \\
\hline \multicolumn{6}{|l|}{ Education Level } \\
\hline Non Formal & $1851(44.7)$ & 88.3(85.3-90.7) & $4.1(2.8-5.4)$ & $44.6(40.4-49.1)$ & $3.9(2.9-5.2)$ \\
\hline Primary & $102(24.6)$ & 95.8(94.1-97.1) & 7.0(4.6-10.4) & $71.6(66.5-76.1)$ & $4.0(2.6-6.0)$ \\
\hline Secondary & $773(18.7)$ & 98.9(97.9-99.5) & $13.5(10.5-17.2)$ & 85.3(80.8-88.9) & $2.9(1.9-4.4)$ \\
\hline Higher Secondary or above & $498(12.0)$ & $98.8(96.1-99.6)$ & 19.0(14.4-24.6) & $92.8(89.6-95.1)$ & $5.3(3.2-8.7)$ \\
\hline \multicolumn{6}{|l|}{ Marital Status ${ }^{a}$} \\
\hline Never Married & $336(8.1)$ & 98.2(95.8-99.3) & 16.2(11.9-21.6) & 85.2(78.7-90.0) & $3.5(1.9-6.5)$ \\
\hline Currently Married & $3568(86.2)$ & $94.7(93.4-95.8)$ & $8.7(7.1-10.6)$ & $68.2(64.6-71.6)$ & $4.0(3.1-5.2)$ \\
\hline Divorced/Widowed/Separated & $237(5.7)$ & $79.1(71.5-85.2)$ & $4.6(2.4-7.6)$ & $49.9(42.1-57.8)$ & $5.4(2.8-9.0)$ \\
\hline Total & 4143 & $94.9(93.8-96.0)$ & $9.9(8.2-11.9)$ & 71.4(67.9-74.7) & $3.9(3.1-5.0)$ \\
\hline
\end{tabular}

${ }^{\mathrm{a}}$ Two refused response

1.5-3.4) than rural residents. People with higher secondary education and above had greater odds (AOR: 14.3; 95 \% CI: 8.7-23.7) of using fluoridated toothpaste, compared to those with non-formal education (Table 2).

\section{Visited a dentist within the last 6 months}

People in the oldest age group, 45-69 years, had higher odds (AOR: 3.6; $95 \%$ CI: 1.8-7.1) of having sought dental services in the last 6 months than those in the youngest age group, 15-29 years. Likewise, women had higher odds of seeking dental services (AOR: 2.2; $95 \%$ CI: 1.2-3.8) than men and the urban population had greater odds (AOR: 1.9, $95 \%$ CI: 1.1-3.6) than the rural. Higher secondary or above education holders had 3 times higher odds of utilizing dental services compared to those with non-formal education (Table 2).

\section{Discussion}

This study provides a snapshot of oral hygiene practices and their socio-demographic correlates among the adult population of Nepal. As is strongly fostered by the National Oral Health Policy 2014 on the execution of oral health related surveys [10], the findings yielded by this countrywide study provide a strong basis from which to commence oral health promotion interventions.

We found a mixed result of the selected oral hygiene practices that are included in this paper with a substantial proportion of people cleaning teeth at least once a day and using fluoridated toothpaste. On the other hand, only a small proportion cleaned teeth at least twice a day. Oral hygiene practices are directly linked with several oral and periodontal disorders $[4,17]$ and are also linked to some chronic conditions $[18,19]$. This hints the need of strategies to promote oral hygiene practices for preventing oral diseases as well as some other chronic conditions. Integrating oral diseases into prevention and control of NCDs could be beneficial as they share the common risk factors such as tobacco use, alcohol consumption, and unhealthy diets high in sugar [2]. Only one in ten respondents was found to be cleaning 
Table 2 Socio-demographic correlates of oral hygiene practices

\begin{tabular}{|c|c|c|c|c|c|c|c|c|}
\hline & \multicolumn{2}{|c|}{ Cleaning teeth at least once a day } & \multicolumn{2}{|c|}{ Cleaning teeth at least twice a day } & \multicolumn{2}{|c|}{ Use of fluoridated toothpaste } & \multicolumn{2}{|c|}{ Visited a dentist within the last 6 months } \\
\hline & Crude OR & Adjusted OR & Crude OR & Adjusted OR & Crude OR & Adjusted OR & Crude OR & Adjusted OR \\
\hline \multicolumn{9}{|l|}{ Age Group (Years) } \\
\hline $15-29$ & 1 & 1 & 1 & 1 & 1 & 1 & 1 & 1 \\
\hline $30-44$ & $0.38(0.22-0.63)$ & $0.6(0.4-1.1)$ & $0.6(0.4-0.8)$ & $0.9(0.6-1.3)$ & $0.6(0.5-0.7)$ & $1.1(0.8-1.4)$ & $1.4(0.9-2.4)$ & $2.0(1.0-3.8)$ \\
\hline $45-69$ & $0.17(0.10-0.29)$ & $0.4(0.2-0.8)$ & $0.4(0.3-0.6)$ & $0.9(0.6-1.4)$ & $0.4(0.3-0.5)$ & $0.9(0.7-1.2)$ & $2.2(1.3-3.5)$ & $3.6(1.8-7.1)$ \\
\hline \multicolumn{9}{|l|}{ Gender } \\
\hline Men & 1 & 1 & 1 & 1 & 1 & 1 & 1 & 1 \\
\hline Women & $0.7(0.4-0.9)$ & $1.3(0.9-1.91)$ & $1.1(0.8-1.5)$ & $1.7(1.1-2.4)$ & $0.6(0.5-0.8)$ & $1.2(0.9-1.5)$ & $1.6(0.9-2.7)$ & $2.2(1.2-3.8)$ \\
\hline \multicolumn{9}{|l|}{ Ecological Belt } \\
\hline Hill & 1 & 1 & 1 & 1 & 1 & 1 & 1 & 1 \\
\hline Mountain & $0.4(0.2-0.8)$ & $0.5(0.2-1.1)$ & $0.4(0.6-2.4)$ & $0.5(0.8-3.3)$ & $0.8(0.5-1.4)$ & $1.1(0.7-1.8)$ & $1.1(0.4-3.5)$ & $1.6(0.5-5.2)$ \\
\hline Terai & $4.4(2.7-7.0)$ & $4.9(3.1-7.8)$ & $1.0(0.7-1.6)$ & $1.1(0.7-1.7)$ & $0.7(0.5-0.9)$ & $0.7(0.5-0.9)$ & $1.0(0.6-1.7)$ & $1.2(0.6-2.1)$ \\
\hline \multicolumn{9}{|l|}{ Residence } \\
\hline Rural & 1 & 1 & 1 & 1 & 1 & 1 & 1 & 1 \\
\hline Urban & $2.1(1.0-4.5)$ & $1.5(0.7-3.1)$ & $2.0(1.3-3.2)$ & 1.6(0.9-2.6) & $2.8(1.9-4.4)$ & $2.3(1.5-3.4)$ & $2.1(1.2-3.5)$ & $1.9(1.1-3.6)$ \\
\hline \multicolumn{9}{|l|}{ Education Level } \\
\hline Non Formal & 1 & 1 & 1 & 1 & 1 & 1 & 1 & 1 \\
\hline Primary & $3.1(2.0-4.6)$ & $3.0(2.0-4.4)$ & $1.8(1.2-2.9)$ & $2.0(1.2-3.1)$ & $3.1(2.4-3.9)$ & $3.0(2.4-4.0)$ & $1.0(0.6-1.7)$ & 1.6(1.0-2.6) \\
\hline Secondary & $13.0(6.0-28.1)$ & $10.3(4.4-24.0)$ & $3.8(2.6-5.7)$ & $4.0(2.4-6.3)$ & $7.2(5.3-9.9)$ & 7.2(5.1-10.3) & $0.7(0.5-1.1)$ & $1.4(0.8-2.4)$ \\
\hline Higher & $11.2(3.1-40.2)$ & $9.0(2.9-27.7)$ & $5.7(3.7-9.0)$ & $5.6(2.9-10.6)$ & $16.0(10.6-24.3)$ & $14.3(8.7-23.7)$ & $1.3(0.8-2.4)$ & $2.8(1.4-5.4)$ \\
\hline \multicolumn{9}{|l|}{ Marital Status } \\
\hline Never Married & 1 & 1 & 1 & 1 & 1 & 1 & 1 & 1 \\
\hline Currently Married & $0.3(0.1-0.8)$ & $1.1(0.4-2.6)$ & $0.5(0.6-2.4)$ & $0.8(0.4-1.2)$ & $0.4(0.2-0.6)$ & $0.9(0.5-1.5)$ & $1.1(0.6-2.2)$ & $0.7(0.3-1.7)$ \\
\hline Divorced/Widowed/Separated & $0.1(0.0-0.2)$ & $0.4(0.2-1.1)$ & $0.2(0.7-1.6)$ & $0.6(0.2-1.3)$ & $0.2(0.1-0.3)$ & $0.8(0.4-1.5)$ & $1.5(0.6-3.5)$ & $0.7(0.2-2.0)$ \\
\hline
\end{tabular}


teeth twice a day, a marked differences with the findings of similar studies done in Denmark (68.0\%) and Kuwait $(62.0 \%)[4,20]$. While this figure was $32.0 \%$ among $35-$ 44 year-olds and $23.0 \%$ among $65-74$ year-olds Chinese [21]. Nevertheless, cleaning teeth at least once a day was nearly universal in this study (Table 1). Other studies have reported this figure to be quite low as $32.0 \%[20]$. Among those cleaning teeth, $88.2 \%$ used toothbrush for cleaning their teeth in this study [11]. Variation in predisposing factors (oral health-related knowledge, attitudes, beliefs, perceptions and values), enabling factors (accessibility and availability of toothbrushes and toothpaste), together with different study sites, time, methodologies and nature of samples may account for this difference. Moreover, it could be explained as a lack of awareness among Nepalese population, as this picture was lowest among the non-formal education holders (Table 1). Nepal is a developing country with lower literacy rate [22] and higher poverty [23] which might have some linkage with the teeth cleaning habits. This is further supported by other findings in our study which revealed that odds of cleaning teeth twice a day and use of fluoridated toothpaste rose with a rise in educational level (Table 2). Previous studies have also documented more chances of teeth cleaning habit among educated people $[4,7,20]$.

Women had higher odds of brushing teeth twice a day than men (Table 2), parallel to the conclusion of prior studies $[4,7]$. Good oral hygiene behavior among women has been reported in various literatures [20, 24, 25]. The majority of the sampled women in the current study were homemakers (Table not shown), thus having flexible time. Being homemakers [26] and having flexible daily routine [27] have been suggested to promote higher teeth-cleaning behavior. Also, women are more motivated to follow oral hygiene practices, perhaps because of aesthetic value and more leisure time (major proportion of sampled women were housewives). Further evidence was illustrated by the current study with the higher odds of dental visit among the women (Table 2), and this goes in line with a previous study [28].

Fluoridated toothpaste use was common (71.4 \%) in this study, higher than those documented by studies in Africa (18.0 \%) [8] and China (5.0 \%) [21]. Urban residents had twice greater odds of using fluoridated toothpaste than did the rural residents (Table 2) giving the idea that place of residence does matter in teeth cleaning habits, although the factors creating these differences might be the subject of further study. Sometimes, people in rural areas of Nepal clean their teeth with bamboo sticks, sacred twigs (dattiwan), Neem, charcoal, and salt in place of fluoridated toothpaste, which might not have been reported. Moreover, higher accessibility, availability, and variety of fluoridated toothpaste in urban areas of Nepal might have contributed to this variation. In line with an African study that found infrequent dental visits $[7,8]$, only four out of 100 respondents in this study reported visiting a dentist in the last 6 months. This contrasts with a western study that found nearly universal 6-monthly dental visits among the population [29], and with a Chinese study that reported a quarter of respondents making a dental visit in the last 12 months [21]. These differences may be explainable by oral health issues not drawing sufficient attention in Nepal, there being a lack of awareness on oral health issues, and a scarcity of dental health professionals [10]. Community education initiatives principally focusing on the importance of fluoride [30], fluoridated toothpaste and teeth cleaning twice a day as a means to fight oral health problems could be of importance $[4,17]$.

This study identified higher odds of dental visits in the last 6 months among the oldest age group, 45-69 years (Table 2), alike to the previous study with marked use of dental care among 45-64 years Swedish adults [6]. Logical assumption can be made that this age group might have more dental problems than the younger age group, as reportedly, burden of oral disease is concentrated more among the older people [31].

Like shown in earlier study $[6,28]$, the current study showed higher chances of dental visit among higher education holders than people with non-formal education. In comparison to rural residents, urban dwellers had two times higher odds of visiting a dentist within the last 6 months (Table 2). This could be argued to relate to the greater availability of sophisticated dental health services in urban areas of Nepal [10].

There is a strong need for the promotion of oral hygiene, as most of the Nepalese people cannot afford the costly treatments for dental diseases. Effective use of fluoride has been recommended as one of the important strategies to promote oral health at the population level [32]. Possibility of water fluoridation in Nepal is currently not feasible, with the lack of single supply system of water, rather salt fluoridation could be a possibility but has not started yet in Nepal [30].

Despite its robust design, this study suffered some limitations, such as a failure to provide evidence of causality for the socio-demographic correlates identified. Nevertheless, the large number of samples, representativeness of samples, and use of standardized tool ensured the reliability of the study.

Nonetheless, there is need for further studies in this domain - not only studies which draw subjective explanations for oral health conditions, but national oral health surveys using objective methods of examining oral health conditions. 


\section{Conclusion}

We found good oral hygiene practices especially cleaning teeth at least once a day and use of fluoridated toothpaste. However, cleaning teeth twice a day and visiting a dentist is less common. Being women, Terai residents, urban dwellers and educated were significantly associated with oral hygiene practices assessed in this study. Relevant stakeholders need to focus on promoting dental visits for dental care where feasible and making use of fluoridated toothpaste universal.

\section{Additional files}

Additional file 1: Oral Hygiene Nepal Data. (XLSX 719 kb)

Additional file 2: Code Book (STEPS Nepal 2013 Instruments). (PDF 340 kb)

\section{Abbreviations}

AOR: Adjusted odds ratio; Cl: Confidence interval; DHO: District Health Office; DPHO: District Public Health Office; ERB: Ethical Review Board; NCD: Non communicable disease; NHRC: Nepal Health Research Council; OR: Odds ratio; PDA: Personal digital assistant; PPS: Probability proportionate to size; PSU: Primary sampling unit; SPSS: Statistical package for the social sciences; SSU: Secondary sampling unit; TSU: Tertiary sampling unit; VDC: Village Development Committee; WHO: World Health Organization

\section{Acknowledgements \\ We sincerely acknowledge the support of study team members, steering committee members, and field supervisors for their technical support during design and implementation of the nationwide STEPS Survey Nepal 2013, from which this manuscript has been prepared. Heartfelt gratitude is offered to the respondents for their voluntary participation. We acknowledge the technical support by Dr Regina Guthold, Ms Melanie Cowan, Dr Leanne Margaret Riley from WHO headquarters and Dr Renu Madanlal Garg from WHO South East Asia Regional Office. A special tribute is paid to the Government of Nepal and the WHO country office Nepal for financial support to carry out the survey. We would also like to extend our sincere thanks to Mr. David Norrish for his contribution in copy editing of the manuscript.}

\section{Funding}

Government of Nepal funded this study with a partial funding by $\mathrm{WHO}$ country office for Nepal. The funding body was not involved in the design of the study and collection, analysis, and interpretation of data and in writing the manuscript.

\section{Availability of data and materials}

The dataset supporting the conclusions of this article is included within the article (and its Additional files 1 and 2).

\section{Authors' contribution}

PT developed the manuscript and assisted in analysis and interpretation of the findings. KKA, SM and AV designed the study and reviewed the manuscript. SM, KKA and BB analyzed the data and interpreted the findings. BKJ assisted in designing the study and performing the experiment. MD interpreted the findings and reviewed the manuscript. SP designed the study, contextualized the instruments to Nepalese context and reviewed the manuscript. PD and KBK analysed data, interpreted findings, and reviewed the manuscript. AP, ARP, BB and AUP reviewed the manuscript. All authors read and approved the final manuscript.

\section{Authors' information}

Dr. Krishna Kumar Aryal is the principal investigator of the Non-Communicable Diseases Risk Factors: STEPS Survey Nepal 2013. Dr. Khem Bahadur Karki was the co-principal investigator of Nepal Non-Communicable Disease Risk Factors Survey, 2008

\section{Competing interests}

The authors declare that they have no competing interests.

Consent for publications

Not applicable.

Ethics approval and consent to participate

Ethical approval was obtained from the independent Ethical Review Board (ERB) of the Nepal Health Research Council (NHRC). The reference number of the ethical approval was 165/2012 and written consent was obtained from the participants of the study. Formal permission was also obtained from the District Health Office (DHO)/District Public Health Office (DPHO) of the selected districts. Research respondents were provided with an information sheet containing detailed information about the research, and written consent was obtained accordingly.

\section{Author details}

${ }^{1}$ Nepal Health Research Council, Ramshahpath, Kathmandu 44600, Nepal. ${ }^{2}$ Nepal Health Sector Support Program, Ministry of Health, Kathmandu 44600, Nepal. ${ }^{3}$ Kathmandu Medical College, Sinamangal, Kathmandu 44600, Nepal. ${ }^{4}$ National Academy of Medical Sciences, Kathmandu 44600, Nepal. ${ }^{5}$ Nobel Medical College and Teaching Hospital, Morang 56600, Nepal.

Received: 16 October 2015 Accepted: 9 June 2016

Published online: 29 September 2016

\section{References}

1. Petersen PE. The World Oral Health Report 2003: continuous improvement of oral health in the 21 st century-the approach of the WHO Global Oral Health Programme. Community Dent Oral Epidemiol. 2003;31(s1):3-24.

2. Petersen PE, Bourgeois D, Ogawa H, Estupinan-Day S, Ndiaye C. The global burden of oral diseases and risks to oral health. Bull World Health Organ. 2005;83(9):661-9.

3. Marcenes W, Kassebaum N, Bernabé E, Flaxman A, Naghavi M, Lopez A, et al. Global burden of oral conditions in 1990-2010 a systematic analysis. J Dent Res. 2013. doi:10.1177/0022034513490168.

4. Al-Shammari KF, Al-Ansari JM, Al-Khabbaz AK, Dashti A, Honkala EJ. Selfreported oral hygiene habits and oral health problems of Kuwaiti adults. Med Princ Pract. 2007;16(1):15-21.

5. World Health Organization. The world health report 2003: shaping the future. Geneva: World Health Organization; 2003.

6. Hjern A, Grindefjord M, Sundberg H, Rosén M. Social inequality in oral health and use of dental care in Sweden. Community Dent Oral Epidemiol. 2001;29(3):167-74

7. Olusile AO, Adeniyi AA, Orebanjo O. Self-rated oral health status, oral health service utilization, and oral hygiene practices among adult Nigerians. BMC Oral Health. 2014;14(1):140.

8. Varenne B, Petersen PE, Ouattara S. Oral health behaviour of children and adults in urban and rural areas of Burkina Faso, Africa. Int Dent J. 2006;56(2):61-70

9. Department of Health Services: National Oral Health Policy 2014. Kathmandu: Oral Health Focal Point, Management Division, Department of Health Services; 2014.

10. Yee R, Mishra P. Nepal National Oral Pathfinder Survey 2004. J Nepal Dent Assoc. 2005;7(1):64-8.

11. Aryal K, Neupane S, Mehata S, Vaidya A, Singh S, Paulin F, et al. Non communicable diseases risk factors: STEPS survey Nepal 2013. Kathmandu: Nepal Health Research Council; 2014

12. Central Bureau of Statistics. Nepal Living Standards Survey 2010/11. Kathmandu: Central Bureau of Statistics; 2011.

13. Aryal KK, Mehata S, Neupane S, Vaidya A, Dhimal M, Dhakal P, et al. The burden and determinants of non communicable diseases risk factors in Nepal: findings from a Nationwide STEPS survey. PLOS One. 2015;10(8):e0134834

14. Nongkynrih B, Acharya A, Ramakrishnan L, Ritvik, Anand K, Shah B. Profile of biochemical risk factors for non communicable diseases in urban, rural and periurban Haryana, India. J Assoc Physicians India. 2008;56:165-70.

15. Ezzati M, Vander Hoorn S, Lawes CM, Leach $R$, James WP, Lopez AD, et al. Rethinking the "diseases of affluence" paradigm: global patterns of nutritional risks in relation to economic development. PLoS Med. 2005;2(5):e133. 
16. Ministry of Health and Population (MOHP) [Nepal], New ERA, ICF International Inc:: Nepal Demographic Health Survey 2011. Kathmandu: Ministry of Health and Population, New ERA, and ICF International; 2012.

17. Doifode V, Ambadekar N, Lanewar A. Assessment of oral health status and its association with some epidemiological factors in population of Nagpur, India. Indian J Med Sci. 2000;54(7):261.

18. Balaram P, Sridhar H, Rajkumar T, Vaccarella S, Herrero R, Nandakumar A, et al. Oral cancer in southern India: The influence of smoking, drinking, paanchewing and oral hygiene. Int J Cancer. 2002;98(3):440-5.

19. Moreno-Lopez L, Esparza-Gomez G, Gonzalez-Navarro A, Cerero-Lapiedra R Gonzalez-Hernandez M, Domınguez-Rojas V. Risk of oral cancer associated with tobacco smoking, alcohol consumption and oral hygiene: a case-control study in Madrid, Spain. Oral Oncol. 2000;36(2):170-4.

20. Christensen LB, Petersen PE, Krustrup U, Kjøller M. Self-reported oral hygiene practices among adults in Denmark. Community Dent Health. 2003;20(4):229-35.

21. Zhu L, Petersen PE, Wang HY, Bian JY, Zhang BX. Oral health knowledge, attitudes and behaviour of adults in China. Int Dent J. 2005;55(4):231-41.

22. The World Bank. Adult literacy rate, population 15+ years, both sexes (\%). [cited 2016 Jan 5]; Available from: http://data.worldbank.org/indicator/SE. ADT.LITR.ZS?end=2010\&locations=NP\&start=1996.

23. The World Bank. Poverty headcount ratio at $\$ 1.90$ a day (2011 PPP) (\% of population). [cited 2016 Jan 5]; Available from: http://data.worldbank.org/ indicator/SI.POV.DDAY?locations=NP.

24. Jensen O, Gabre P, Sköld UM, Birkhed D. Is the use of fluoride toothpaste optimal? Knowledge, attitudes and behaviour concerning fluoride toothpaste and toothbrushing in different age groups in Sweden. Community Dent Oral Epidemiol. 2012;40(2):175-84.

25. Tseveenjav B, Suominen AL, Hausen H, Vehkalahti MM. The role of sugar, xylitol, toothbrushing frequency, and use of fluoride toothpaste in maintenance of adults' dental health: findings from the Finnish National Health 2000 Survey. Eur J Oral Sci. 2011;119(1):40-7.

26. Kumar S, Nigam A, Choudhary A, Tadakamadla J, Tibdewal H, Duraiswamy P, et al. Influence of lifestyle on oral health behavior among rural residents of Udaipur district, India. Med Oral Patol Oral Cir Bucal. 2011;16:e828-33.

27. Abegg C, Croucher R, Marcenes WS, Sheiham A. How do routines of daily activities and flexibility of daily activities affect tooth-cleaning behavior? J Public Health Dent. 2000;60(3):154-8.

28. Lo $E$, Lin $H$, Wang $Z$, Wong $M$, Schwarz E. Utilization of dental services in Southern China. J Dent Res. 2001;80(5):1471-4.

29. Kronström M, Palmqvist S, Söderfeldt B, Vigild M. Utilization of dental health services among middle-aged people in Sweden and Denmark. Acta Odontol. 2002;60(5):276-80.

30. Petersen P, Baez R, Lennon M. Community-oriented Administration of fluoride for the prevention of dental caries a summary of the current situation in Asia. Adv Dent Res. 2012;24(1):5-10.

31. Petersen PE, Yamamoto T. Improving the oral health of older people: the approach of the WHO Global Oral Health Programme. Community Dent Oral Epidemiol. 2005;33(2):81-92.

32. Petersen $\mathrm{PE}$, Lennon MA. Effective use of fluorides for the prevention of dental caries in the 21st century: the WHO approach. Community Dent Oral Epidemiol. 2004;32(5):319-21.

\section{Submit your next manuscript to BioMed Central and we will help you at every step:}

- We accept pre-submission inquiries

- Our selector tool helps you to find the most relevant journal

- We provide round the clock customer support

- Convenient online submission

- Thorough peer review

- Inclusion in PubMed and all major indexing services

- Maximum visibility for your research

Submit your manuscript at www.biomedcentral.com/submit
Biomed Central 